\title{
Perceived stress due to COVID-19 in Iran: Emphasizing the role of social networks
}

\author{
Azad Shokri ${ }^{1}$, Ghobad Moradi ${ }^{1}$, Bakhtiar Piroozi ${ }^{1}$, Sonia Darvishi ${ }^{1}$, Shina Amirihosseini ${ }^{1}$, Arshad Veysi $^{2}$, Fatemeh Manafi ${ }^{3}$, \\ Amjad Mohamadi Bolbanabad*1 (1)
}

Received: 24 Mar 2020

Published: 30 May 2020

Conflicts of Interest: None declared

Funding: The study was financially supported by Kurdistan University of Medical Sciences, Sanandaj, Iran.

\author{
*This work has been published under CC BY-NC-SA 1.0 license. \\ Copyright $\subseteq$ Iran University of Medical Sciences
}

Cite this article as: Shokri A, Moradi Gh, Piroozi B, Darvishi S, Amirihosseini Sh, Veysi A, Manafi F, Mohamadi Bolbanabad A. Perceived stress due to COVID-19 in Iran: Emphasizing the role of social networks. Med J Islam Repub Iran. 2020 (30 May);34:55. https://doi.org/10.47176/mjiri.34.55

\section{Brief communication}

COVID-19 belongs to Coronaviridae family and was identified in December 2019; since then, it has been spread to more than 200 countries worldwide, raising widespread fear and anxiety among people, particularly high-risk groups (1). Scientists across the globe are strictly working on the different aspects of the disease, including mechanisms of transmission, clinical spectrum, new diagnostic approach, and prevention and treatment strategies to reduce the concerns about this disease $(2,3)$. However, the recent sharp rise of mortality rates and claims of the national and abroad experts regarding Iran's lack of preparedness for COVID-19 epidemic have caused increasing anxiety and panic among the Iranian community. On the other hand, the unknown nature of the disease has worsened the situation in Iran. However, the anxiety caused by this disease harms people even more than the Coronavirus itself (4). In an outbreak, people may be frightened for their own health or their family members', which may have negative effects on their sleep or dietary patterns, concentration, and may even

Corresponding author: Dr Amjad Mohamadi Bolbanabad, a.mohammadib@muk.ac.ir

1. Social Determinants of Health Research Center, Research Institute for Health Development, Kurdistan University of Medical Sciences, Sanandaj, Iran

2. Zoonoses Research Center, Research Institute for Health Development, Kurdistan University of Medical Sciences, Sanandaj, Iran

3. Department of Health Management and Economics, School of Public Health, Tehran University of Medical Sciences, Tehran, Iran lead to chronic health problems. In some cases, it even increases the use of alcohol, tobacco, or other drugs (5). Therefore, anxiety in reaction to COVID-19 may cause great harm to people and can lead to some implications which raise more concerns than the Coronavirus itself. In many cases, these people look for different sources of information to ease anxiety and uncertainty and easily access the stimulating news. Due to the spread of the Coronavirus in Iran and the importance of fear in the society, the present study investigated the perceived stress of COVID-19 disease in different groups in the society.

This descriptive-analytical study was conducted in March-April 2020, after a month passing from the COVID19 epidemic in Iran. The study population included all individuals living in Iran. The perceived stress scale developed by Cohen et al (1983) was used to collect data. This scale includes 14 questions and the scores range from 0 to 4 on the Likert scale: 0 (never), 1 (rarely), 2 (sometimes), 3 (most often), and 4 (always) (6). In the demographic part, questions regarding fear symptoms and risk groups reported on the WHO website were used (7). People were also asked where they mostly get information on the new

\section{$\uparrow$ What is "already known" in this topic:}

Rising mortality rate due to Corona virus (COVID- 19) has raised anxiety and panic among the Iranian community. This reaction to COVID-19 may cause harm to people and even lead to some implications which raise more concerns than the Coronavirus itself. Previous research has shown that receiving this stimulating news has the same effect as posttraumatic stress and depression.

\section{$\rightarrow$ What this article adds:}

This study showed that perceived stress due to COVID-19 in Iranian society was slightly high and receiving news and information from social networks has an impact on increasing perceived stress in the community. 
cases, mortality, and disease control tips. To investigate the source of information, people were placed in the 2 groups: (1) people who got information from official and valid sources, including the national television channels, Medical University channels, Health care Channels, and other official channels; (2) people who got their information from social and invalid networks, including Instagram pages, Telegram channels/ groups, satellite channels, and other unofficial channels. Eight researchers collected data (information that was sent to participants in 2 weeks) electronically through email, mobile SMS, Facebook, Instagram direct, WhatsApp direct, and Telegram groups. Data were analyzed using ANOVA, t test, and multiple linear logistic model to examine the relationship between different variables and the rate of Coronavirus fear based on the source of information.

A total of 700 people, with the mean age of $32.82 \pm 10.26$ years, participated in this study. Most of participants were women $(65 \%)$, held postgraduate and higher education degree $(43 \%)$, and were government employees $(37 \%)$.
The mean perceived stress among the participants was $28.80 \pm 7.12$ and was significantly higher $(\mathrm{P}>0.001)$ among social media users. This relationship was significant among all subgroups (Table 1). The results also indicated that the highest average fear was for high-risk groups in families and people with Coronavirus symptoms.

The results of multiple linear regression showed that in all models, users of social networks had significantly higher mean perceived stress $(\mathrm{P}<0.05)$ (Table 2$)$. For example, users of social networks had 2.16 units of perceived stress $(\mathrm{P}<0.001,95 \% \mathrm{CI}: 1.06-3.25)$ more than official source users. Modified models also obtained the same results. Stress was even up to 2.44 among women $(\mathrm{P}<0.001,95 \% \mathrm{CI}$ : 1.07-3.78).

This study was the first on Corona-induced stress in Iran and showed high levels of perceived stress in Iranian society. Perceived stress was higher among those who followed the news of COVID-19 in social networks compared to others in the community.

Table 1. Mean perceived stress by information sources among participants

\begin{tabular}{|c|c|c|c|c|c|}
\hline & & Official news sources & Social networks & Total & $\mathrm{P}$ value \\
\hline \multicolumn{6}{|l|}{ Age } \\
\hline $30>$ & & $26.72 \pm 7.35$ & $29.40 \pm 7.23$ & $28.53 \pm 7.37$ & 0.020 \\
\hline $30-40$ & & $29.06 \pm 7.18$ & $29.99 \pm 6.78$ & $29.69 \pm 6.91$ & 0.359 \\
\hline$>40$ & & $26.81 \pm 6.84$ & $29.14 \pm 7.02$ & $28.09 \pm 7.01$ & 0.050 \\
\hline \multicolumn{6}{|l|}{ Sex } \\
\hline Female & & $28.13 \pm 7.10$ & $30.56 \pm 7.03$ & $29.67 \pm 7.14$ & $<0.001$ \\
\hline Male & & $25.86 \pm 6.88$ & $27.87 \pm 6.62$ & $27.22 \pm 6.75$ & 0.031 \\
\hline \multicolumn{6}{|l|}{ Education } \\
\hline Academic & & $27.71 \pm 7.18$ & $29.67 \pm 7.01$ & $28.89 \pm 7.13$ & 0.001 \\
\hline Non-academic & & $25.48 \pm 6.40$ & $28.44 \pm 6.83$ & $27.40 \pm 6.78$ & 0.107 \\
\hline \multicolumn{6}{|l|}{ Employment } \\
\hline Unemployed or housewife & & $25.54 \pm 6.82$ & $28.98 \pm 8.06$ & $28.02 \pm 7.84$ & 0.680 \\
\hline School or university student & & $26.66 \pm 7.27$ & $29.61 \pm 7.29$ & $28.53 \pm 7.40$ & 0.009 \\
\hline Self-employed & & $26.95 \pm 1.48$ & $28.25 \pm 6.49$ & $27.88 \pm 6.58$ & 0.458 \\
\hline Government employee & & $28.54 \pm 7.149$ & $30.70 \pm 6.70$ & $29.82 \pm 6.95$ & 0.015 \\
\hline \multicolumn{6}{|l|}{ Marital status } \\
\hline Single & & $27,25 \pm 6.97$ & $28.68 \pm 7.06$ & $28.19 \pm 7.06$ & 0.600 \\
\hline Married & & $27.79 \pm 7.28$ & $30.57 \pm 6.86$ & $29.51 \pm 7.14$ & $<0.001$ \\
\hline \multicolumn{6}{|c|}{ At-risk groups in the family } \\
\hline \multicolumn{6}{|c|}{ Presence of $<10$ members in the family } \\
\hline & Yes & $28,45 \pm 7.12$ & $30.34 \pm 7.24$ & $29.70 \pm 7.25$ & 0.035 \\
\hline & No & $26.70 \pm 7.08$ & $28.99 \pm 6.78$ & $28.17 \pm 6.97$ & 0.010 \\
\hline \multicolumn{6}{|c|}{ Presence of $<60$ members in the family } \\
\hline & Yes & $28.22 \pm 6.74$ & $30.35 \pm 7.19$ & $29.59 \pm 7.09$ & 0.005 \\
\hline & No & $26.46 \pm 7.49$ & $28.7 \pm 6.70$ & $27.93 \pm 7.05$ & 0.006 \\
\hline \multicolumn{6}{|c|}{$\begin{array}{l}\text { Presence of a people with a history of under- } \\
\text { lying diseases in the family }\end{array}$} \\
\hline & Yes & $27.96 \pm 6.46$ & $30.49 \pm 6.65$ & $29.53 \pm 6.68$ & 0.001 \\
\hline & No & $26.81 \pm 7.79$ & $28.77 \pm 7.21$ & $28.13 \pm 7.45$ & 0.019 \\
\hline \multirow{2}{*}{\multicolumn{6}{|c|}{$\begin{array}{l}\text { Symptoms of Corona fear } \\
\text { Fever }\end{array}$}} \\
\hline & & & & & \\
\hline & Yes & $28.52 \pm 6.25$ & $31.39 \pm 5.81$ & $30.51 \pm 6.06$ & 0.048 \\
\hline & No & $27.28 \pm 7.23$ & $29.30 \pm 7.12$ & $28.58 \pm 7.22$ & 0.001 \\
\hline \multicolumn{6}{|l|}{ Cough } \\
\hline & Yes & $28.47 \pm 6.70$ & $30.61 \pm 6.28$ & $29.90 \pm 6.49$ & 0.018 \\
\hline & No & $26.92 \pm 7.29$ & $29.02 \pm 7.29$ & $28.27 \pm 7.36$ & 0.003 \\
\hline \multicolumn{6}{|c|}{ A feeling of weakness or fatigue } \\
\hline & Yes & $27.61 \pm 6.74$ & $30.76 \pm 7.18$ & $29.72 \pm 7.18$ & 0.002 \\
\hline & No & $27.32 \pm 7.32$ & $28.96 \pm 6.84$ & $28.36 \pm 7.06$ & 0.015 \\
\hline \multicolumn{6}{|c|}{ Shortness of breath or discomfort in the chest } \\
\hline & Yes & $29.63 \pm 7.13$ & $31.81 \pm 6.63$ & $31.11 \pm 6.851$ & 0.076 \\
\hline & No & $26.90 \pm 7.06$ & $28.96 \pm 6.99$ & $28.22 \pm 7.07$ & 0.001 \\
\hline Total & & $27.41 \pm 7.14$ & $29.56 \pm 7.00$ & $28.80 \pm 7.12$ & $<0.001$ \\
\hline
\end{tabular}


Table 2. Multiple linear regression results for investigating the relationship between information sources and perceived stress from Corona disease in general classes and both sexes

\begin{tabular}{|c|c|c|c|c|c|}
\hline & & \multirow[t]{2}{*}{ B* } & \multicolumn{2}{|c|}{ Confidence interval 95\% } & \multirow[t]{2}{*}{ P value } \\
\hline & & & Lower CI & Upper CI & \\
\hline \multicolumn{6}{|l|}{ Total } \\
\hline & Crude & 2.16 & 1.06 & 3.25 & $<0.001$ \\
\hline & Model 1 & 2.29 & 1.19 & 3.40 & $<0.001$ \\
\hline & Model 2 & 2.29 & 1.19 & 3.39 & $<0.001$ \\
\hline & Model 3 & 2.29 & 1.19 & 3.38 & $<0.001$ \\
\hline & Model 4 & 2.19 & 1.11 & 3.28 & $<0.001$ \\
\hline \multicolumn{6}{|c|}{ Gender } \\
\hline \multicolumn{6}{|c|}{ Females } \\
\hline & Crude & 2.42 & 1.07 & 3.78 & $<0.001$ \\
\hline & Model 1 & 2.44 & 1.07 & 3.81 & 0.001 \\
\hline & Model 2 & 2.33 & 0.96 & 3.69 & 0.001 \\
\hline & Model 3 & 2.28 & 0.93 & 3.64 & 0.001 \\
\hline & Model 4 & 2.16 & 0.82 & 3.51 & 0.020 \\
\hline \multicolumn{6}{|c|}{ Males } \\
\hline & Crude & 2.01 & 0.18 & 3.83 & 0.031 \\
\hline & Model 1 & 1.98 & 0.10 & 3.86 & 0.039 \\
\hline & Model 2 & 2.25 & 0.33 & 4.19 & 0.022 \\
\hline & Model 3 & 2.32 & 0.38 & 4.26 & 0.019 \\
\hline & Model 4 & 2.23 & 0.29 & 4.18 & 0.024 \\
\hline
\end{tabular}

Data are presented as OR $(95 \% \mathrm{CI})$

Official sources are the reference.

Model 1: adjusted for age and sex (for Total status-stratified analysis)

Model 2: additionally, adjusted for marital status, education, occupation.

Model 3: further adjustment for high/at risk groups in the family.

Model 4: more adjustments for feel symptoms of the Corona virus.

According to the results of this study, average perceived stress in the community was $28.80 \pm 7.12$. The mean stress perceived by pregnant women during amniocenteses, as one of the methods of diagnosis of fetal abnormalities was $24.74 \pm 7.7$, which was much lower than the present study (7). Also, the perceived stress among individuals with cumulative trauma disorders caused by upper extremity trauma was $23.9 \pm 7.1$ (6). Therefore, high stress scores in a community can make it vulnerable to the disease (8). Psychologists believe that fear of the unknown has its roots in human instinct that protects humans from possible threats, but in some cases, same as experienced during SARS outbreak, it can exacerbate the disease complication (4).

According to the results of our study, users of social media networks have higher perceived stress than users of official sources. Consistent with our findings, the results of the study of Gao et al (2019) in China showed that the prevalence of mental health problems, such as depression and anxiety, is correlated with higher exposure to social networks (9). However, some studies showed that social networks have had a significant role in informing and increasing the perceived risk of the community at the time of the MERS epidemic $(6,8)$. The media is a source for triggering anxiety because of their emphasis on bad news. In other words, the media have repeatedly emphasized the rapid spread of the disease and unavailability of treatment. Therefore, limiting the exposure to media, especially those that disseminate inaccurate or unreliable information and providing credible and reliable information to individuals, especially those who feel vulnerable is of paramount importance. Moreover, considering community stress management measures during epidemics, such as COVID-19, along with other preventive and therapeutic interventions, is highly recommended.

\section{Acknowledgments}

We are grateful to all participations for their cooperation during data collection. Moreover, we highly appreciate the financial support of Kurdistan University of Medical Sciences, Sanandaj, Iran.

\section{Conflict of Interests}

The authors declare that they have no competing interests.

\section{References}

1. Cascella M, Rajnik M, Cuomo A, Dulebohn SC, Di Napoli R. Features, evaluation and treatment coronavirus (COVID-19). StatPearls [Internet]: StatPearls Publishing; 2020.

2. Yudkin JS, Kumari M, Humphries SE, Mohamed-Ali V. Inflammation, obesity, stress and coronary heart disease: is interleukin- 6 the link? Atherosclerosis. 2000;148(2):209-14

3. Chen Q, Liang M, Li Y, Guo J, Fei D, Wang L, et al. Mental health care for medical staff in China during the COVID-19 outbreak. Lancet Psychiatry. 2020.

4. Wu P, Fang Y, Guan Z, Fan B, Kong J, Yao Z, et al. The psychological impact of the SARS epidemic on hospital employees in China: exposure, risk perception, and altruistic acceptance of risk. Canad J Psychiatry. 2009;54(5):302-11.

5. Gao J, Zheng P, Jia Y, Chen H, Mao Y, Chen S, et al. Mental health problems and social media exposure during COVID-19 outbreak. Plos One. 2020;15(4):e0231924.

6. Choi DH, Yoo W, Noh GY, Park K. The impact of social media on risk perceptions during the MERS outbreak in South Korea. Comput Hum Behav. 2017;72:422-31

7. World Health Organization. Country \& Technical Guidance Coronavirus disease (COVID-19) 2020 [Available from: https://www. who.int/emergencies/diseases/novel-coronavirus-2019/technical-guid ance.

8. Yoo W, Choi DH, Park K. The effects of SNS communication: How expressing and receiving information predict MERS-preventive behavioral intentions in South Korea. Comput Hum Behav. 2016;62:34-43.

9. Gao J, Zheng P, Jia Y, Chen H, Mao Y, Chen S, et al. Mental Health Problems and Social Media Exposure During COVID-19 Outbreak. PloS One. 2020; 15(4): e0231924. 